\title{
Tribological Behavior of Diamond Coatings against Carbon Fiber Reinforced Plastics under Dry Conditions
}

\author{
Jianguo Zhang \\ College of Mechanical Engineering, Donghua University, Shanghai, China \\ Email: fnzjg@dhu.edu.cn
}

How to cite this paper: Zhang, J.G. (2019) Tribological Behavior of Diamond Coatings against Carbon Fiber Reinforced Plastics under Dry Conditions. Journal of Surface Engineered Materials and Advanced Technology, 9, 45-54.

https://doi.org/10.4236/jsemat.2019.94005

Received: July 22, 2019

Accepted: August 18, 2019

Published: August 21, 2019

Copyright $\odot 2019$ by author(s) and Scientific Research Publishing Inc. This work is licensed under the Creative Commons Attribution International License (CC BY 4.0).

http://creativecommons.org/licenses/by/4.0/

\section{(c) (i) Open Access}

\begin{abstract}
The frictional resistance and machining quality when cutting carbon fiber reinforced plastics (CFRP) laminates are associated with tribological behavior of tool materials. In the present study, the tribological properties of three types of monolayer microcrystalline diamond (MCD) coatings, nanocrystalline diamond (NCD) coatings and dual-layer MCD/NCD coatings sliding against CFRP are investigated under dry lubricated conditions using the rotational friction tester. The coefficients of friction (COF), wear rate and worn surfaces of the contacted surfaces are analyzed for the MCD-CFRP, NCD-CFRP and MCD/NCD-CFRP contacting pairs. The results show that compared with the monolayer MCD and NCD, the bilayer of MCD/NCD coating displays the lowest COF with the value of $\sim 0.13$, it is $42 \%$ and $55 \%$ of the values for MCD and NCD coatings. Due to the rough surfaces of MCD, the wear debris of CFRP on MCD samples exhibits the plowing effect. While for the NCD and MCD/NCD samples, the wear fragments display the planar shapes. The wear rate of CFRP against MCD is more than twice that of CFRP against NCD, due to the excellent loading capacity. While the wear rate of CFRP against MCD/NCD is about twice than that of CFRP-NCD pairs. The bilayer of MCD/NCD combines the excellent advantages of high hardness of MCD and the smooth surface of NCD. It shows the broad application potential for the bilayer coatings.
\end{abstract}

\section{Keywords}

Tribological Behavior, Diamond Coatings, Bilayer Coatings, Carbon Fiber Reinforced Plastics 


\section{Introduction}

Diamond coatings produced by chemical vapor deposition (CVD) combine excellent mechanical and tribological properties, such as high hardness, exceptional wear and corrosion resistance, low friction coefficient against a variety of counterparts [1] [2]. They are widely used as protective and wear-resistant coating for cutting tools, in order to improve the tool life and cutting performance [3] [4]. However, the cutting performance of the coated tools varies with the characterization of as-deposited coatings, such as surface morphology and film structure. According to the film structure, diamond films are mainly classified as the monolayer microcrystalline diamond (MCD) films, monolayer nanocrystalline diamond (NCD) films and bilayer or multilayer composite diamond films. The MCD films have high hardness, high wear resistance and rough surfaces, while the NCD and films have smoother surfaces, but with relative lower hardness. The bilayer or multilayer films possess the hardness of MCD and the smooth surfaces of NCD [5] [6] [7].

Carbon fiber reinforced plastics (CFRP) are increasingly used in the field of aerospace and aircraft, due to their advantages in mechanical properties [8] [9]. However, CFRP are the difficult-to-cut materials because of the anisotropic structure and abrasive nature of carbon fiber. It is generally recognized that diamond films deposited on the surface of the Co-cemented tungsten carbide (WC-Co) tools used for cutting the CFRP have many advantages for the excellent proprieties of diamond coatings [10] [11].

In the cutting process, friction and wear are the crucial issues in the tool-workpiece system. The interaction between tool and workpiece has great impact on the tool life and product quality. Studying on the friction properties of tool and workpiece is an important method to inspect the processing performance. Klinkova et al. studied the friction properties between carbide tools and CFRP work material, the elasto-plastic deformation occurred in parallel to the friction at the interface. The results also showed that the COF is not sensitive to the coatings on carbide pins [12]. Mondelin et al. discussed the friction properties between CFRP and monocrystalline diamond. The results reveal that the COF is not sensitive to sliding velocity or contact pressure, but the layers in CFRP have a limited influence on friction [13]. Lei et al. studied the tribological properties of the diamond films used as an interlayer between TiAlN and WC-Co substrates, the results suggested that the TiAlN/MNCD coatings possess low COF and robust load support capacity [14]. Wang et al. investigated the tribological properties of MCD films synthesized using different carbon sources against stainless steel, the results showed that the MCD films fabricated by methane displayed the more excellent performance due to their smaller grain size and lower surface roughness [15]. Wang et al. compared the tribological behaviors of different diamond films sliding against the CFRP laminates, they concluded that better adhesion provided by the boron doping can effectively prohibit the premature film peeling [16]. All of the above studies provide a perspec- 
tive for steel machining. As to the diamond coated tools in CFRP machining, considering the effect of film structure on CFRP friction could provide guidance for tool selecting.

In the present investigation, the tribotests are conducted on the pairs of CFRP-MCD, CFRP-NCD and CFRP-MCD/NCD films deposited on WC-Co substrates. Furthermore, the field emission scanning electron microscopy (FESEM) and Raman spectroscopy are employed to characterize diamond coated samples and CFRP so as to search for the tribological mechanisms.

\section{Experimental Details}

\subsection{Fabrication of Diamond Films}

The WC-Co flats with the size of $16 \mathrm{~mm} \times 16 \mathrm{~mm} \times 5 \mathrm{~mm}$ are adopted as substrates. Before films depositing, chemical pretreatment procedures for the WC-Co substrates are carried out with Murakami's reagent $\left[\mathrm{K}_{3} \mathrm{Fe}(\mathrm{CN})_{6}\right.$ : $\left.\mathrm{KOH}: \mathrm{H}_{2} \mathrm{O}=1 \mathrm{~g}: 1 \mathrm{~g}: 10 \mathrm{~mL}\right)$ and acid solution $\left(\mathrm{HCl}: \mathrm{H}_{2} \mathrm{O}_{2}=1 \mathrm{~mL}: 4 \mathrm{~mL}\right)$. Afterward, the substrates are diamond seeded by scratching with diamond powders with the size of $\sim 2 \mu \mathrm{m}$. Finally the specimens are dipped into alcohol and cleaned ultrasonically.

The deposition processes are carried out in a home-made HFCVD apparatus. Tantalum wires are used as hot filaments, they are dragged to be straight and fixed above the pretreated WC-Co flats. The methane, hydrogen and argon are adopted as the reactant gas. Three types of diamond coatings, namely microcrystalline diamond (MCD), nanocrystalline diamond ( $\mathrm{NCD}$ ) and composite films of MCD and NCD (MCD/NCD) are deposited on the WC-Co substrates with the settled deposition parameters. The field emission scanning electron microscopy (FESEM Zeiss ULTRA55) is adopted to investigate the morphology of as-fabricated diamond films. The Raman spectroscopy (SPEX1403) is applied to assess composition and purities of all the diamond specimens.

\subsection{Friction Tests}

The tribotests are carried out using the upgrade ball-on-disk rotational friction tester (PCR-T) under the unlubricated ambient air condition. In the tribotests, the CFRP is cut into the wedge shape used as upper-specimen. The WC-Co plates coated with MCD, NCD and MCD/NCD films are clamped on a rotating table, which are used as lower-specimen. The wear rate is calculated by the formula:

$$
W_{\text {CFRP }}=V /\left(F^{*} L\right)
$$

where $V$ is the wear volume, $\mathrm{F}$ is the normal, $L$ is the sliding distance. The wear volume of CFRP is calculate by the weight before and after tribotests. After the tribotests, the FESEM and 3D microscope (KEYENCE VHX-500) are involved in the post-test surface analysis for prevailing wear mechanisms between CFRP and diamond films. The friction coefficients for the contacts are recorded automatically by the friction tester. 


\section{Results and Discussion}

\subsection{Characterization of Diamond Films}

The SEM and AFM micrographs of MCD, NCD and MCD/NCD films are depicted in Figures 1-3. For the MCD films, the average grain size is about $3 \mu \mathrm{m}$. The obvious valley among diamond grains is displayed in the AFM micrographs. As to the NCD films, it presents cauliflower-like clusters with many grain boundaries. During the depositing process of the MCD/NCD, the parameters for the NCD depositing stage is the same to the monolayer NCD. The MCD/NCD films exhibit the similar morphology to the NCD ones with the structure made up of fine crystalline grains.

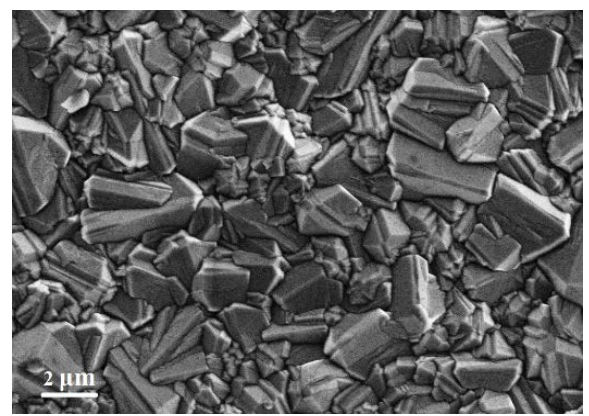

(a)

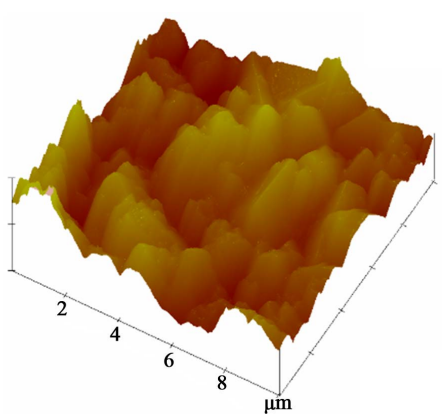

(b)

Figure 1. Surface morphologies of MCD. (a) SEM; (b) AFM.

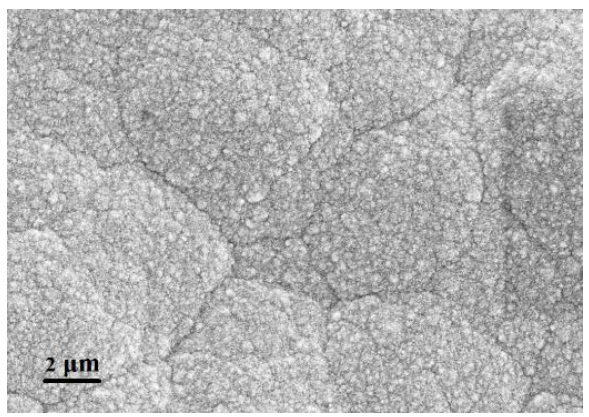

(a)

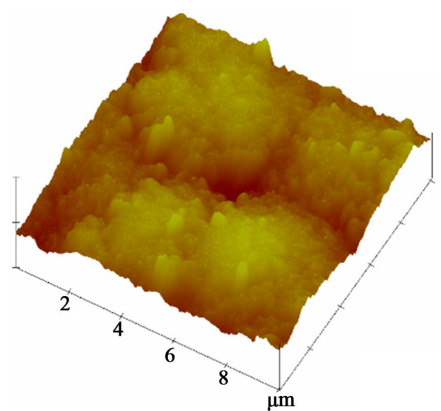

(b)

Figure 2. Surface morphologies of NCD. (a) SEM; (b) AFM.

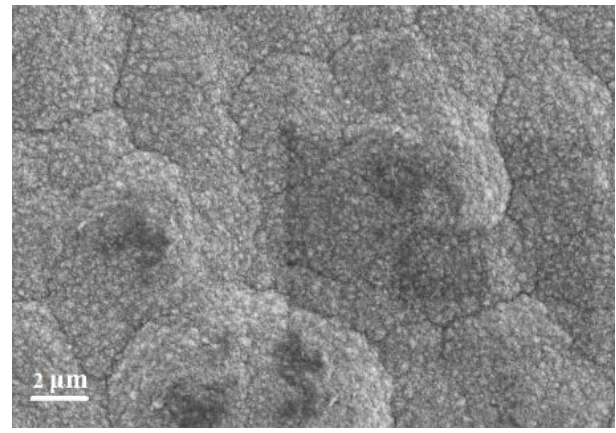

(a)

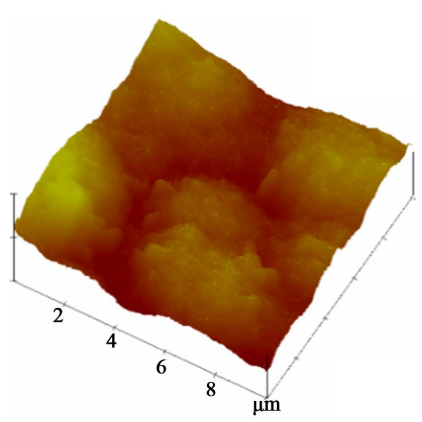

(b)

Figure 3. Surface morphologies of MCD/NCD. (a) SEM; (b) AFM. 
The Raman spectra of the all diamond films are illustrated in Figure 4. It can be seen that there is a sharp peak of $1335.1 \mathrm{~cm}^{-1}$ in the spectrum of MCD films in Figure 4(a). The pronounced peak located around $1332 \mathrm{~cm}^{-1}$ is the characteristic peaks of $\mathrm{sp}^{3}$ diamond phase. The frequency of these peaks shift from the value of natural diamond $\left(1332 \mathrm{~cm}^{-1}\right)$, indicating the residual stress in the films. For the NCD films, there are two broad peaks located at $1330.9 \mathrm{~cm}^{-1}$ and $1579.7 \mathrm{~cm}^{-1}$, that results from the existence of peaks related to the $\mathrm{sp}^{2}$ structure. The peaks around $1331.1 \mathrm{~cm}^{-1}$ and $1565.2 \mathrm{~cm}^{-1}$ of MCD/NCD films display the similar vales of the NCD. It is related to the grain boundary contributions arising from amorphous carbon or graphite located at around $1560-1580 \mathrm{~cm}^{-1}$ [17] [18].

\subsection{Coefficients of Friction}

The average coefficients of friction (COF) and evolution curves of the tested pairs are plotted in Figure 5. All the curves present similar evolution, which contains two stages: rapid transition and dynamic equilibrium steady-state stage [19]. It is found that the CFRP-MCD contacting pair shows the highest COF of $\sim 0.31$, because of the rough surface of MCD films. The COF of the CFRP-NCD and CFRP-MCD/NCD contacting pairs are 0.24 and 0.13 , respectively. It comes from the fact that the nanocrystalline grains on NCD and MC/NCD bring to smooth surfaces, leading to decrease the COF. Additionally, the COF of CFRP-MC/NCD pair is about 50\% of that of CFRP-NCD pair, it is attributed to that the MCD/NCD film is harder than the NCD film, which could improve the

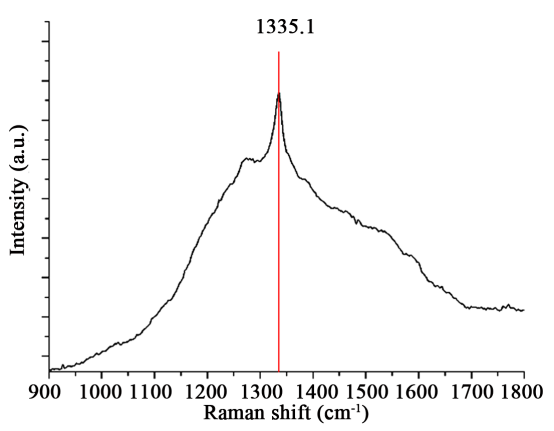

(a)

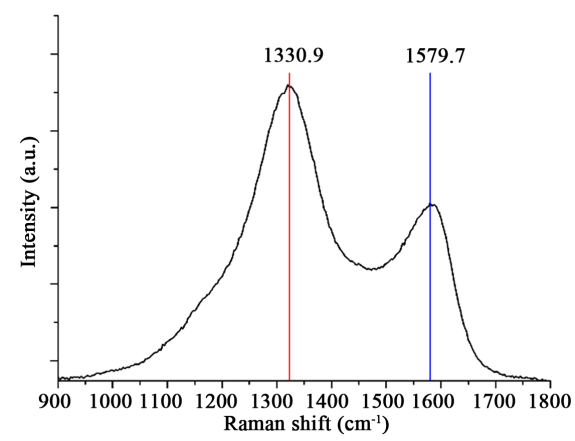

(b)

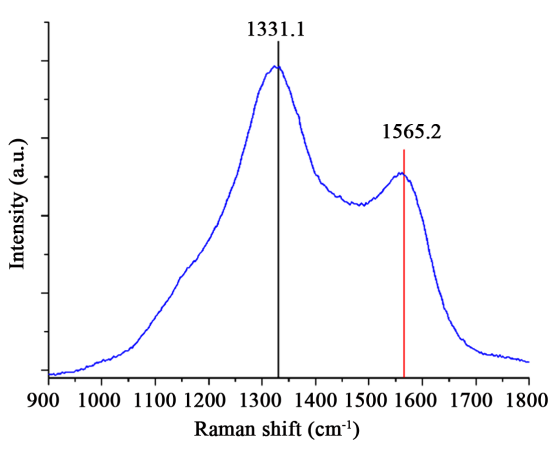

(c)

Figure 4. Raman spectrum of diamond films. (a) MCD; (b) NCD; (c) MCD/NCD. 


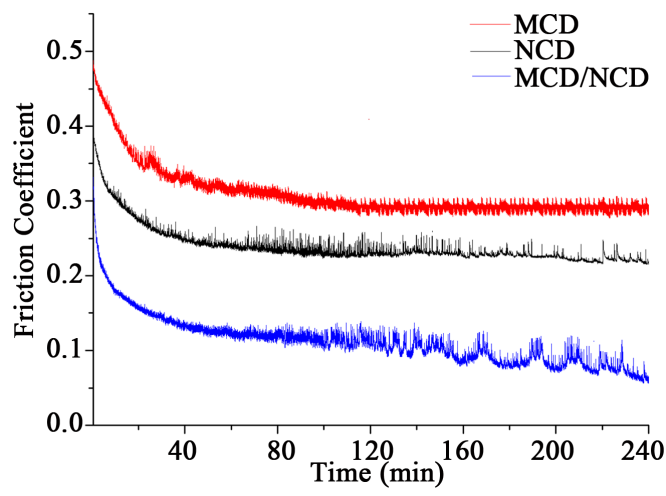

Figure 5. Friction coefficient curves as functions of the time.

antifriction effect. What's more, the hard of MCD film is the highest among the three types of diamond films, the surface roughness of MCD is the dominate impacting factor to COF.

\subsection{Worn Surfaces of Diamond Coating Specimens}

The wear morphologies of all diamond coatings are demonstrated in Figures 6-8. It is noted that the wear debris of CFRP sticks to surfaces with different patterns on diamond films. The micrographs of the MCD surfaces suggest the obvious plowing effect between CFRP of MCD films. The wear debris of CFRP on the NCD and MCD/NCD samples display the planar shapes. But the wear fragments on $\mathrm{MCD} / \mathrm{NCD}$ surfaces present single layer, which is different from that on the NCD surfaces. The roughness of MCD is higher than that of NCD and $\mathrm{MCD} / \mathrm{NCD}$, which leads to the severer wear. There are many fragments on the MCD coated plates, it is caused by the fracture of carbon fibers. Compared to the MCD, the smooth and continuous morphology is observed in Figure 7 and Figure 8. That is caused by the lower hardness of NCD and MCD/NCD, it is easier to combine with the carbon fibers to form the tribofilm compared with the MCD.

\subsection{The Wear Rate}

At the end of the tribotests, the specific wear rates of CFRP in the three contacting pairs are calculated. The removal reduced volume of CRFP is calculated by dividing the reduced mass by the density. In Figure 9, the specific wear rates of CFRP are $95.47 \times 10^{-5} \mathrm{~mm}^{3} \mathrm{~N}^{-1} \cdot \mathrm{m}^{-1}, 44.65 \times 10^{-5} \mathrm{~mm}^{3} \mathrm{~N}^{-1} \cdot \mathrm{m}^{-1}$ and $85.63 \times 10^{-5}$ $\mathrm{mm}^{3} \mathrm{~N}^{-1} \cdot \mathrm{m}^{-1}$, respectively.

From the worn surfaces of CFRP characterized by microscope are shown in Figure 10, the area of contact surfaces during friction is related to the properties of lower-sample of the friction pairs. Because of the rough surfaces and high hardness of MCD, the contact surfaces are prone to be abrasion, which is consistent with the wear rate and high COF. The contact surfaces of CFRP sample contacting with NCD, suggesting the small area of contact surfaces, due to the lower hardness and smoother surfaces. The CFRP sample contacting with 


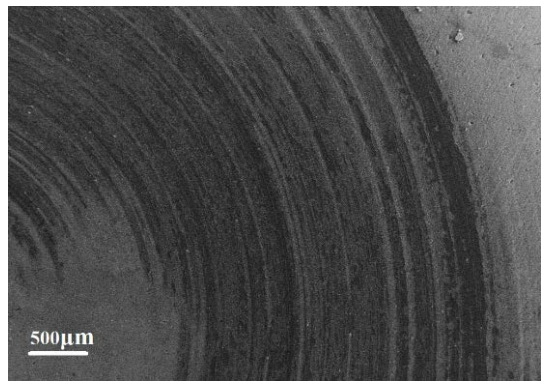

(a)

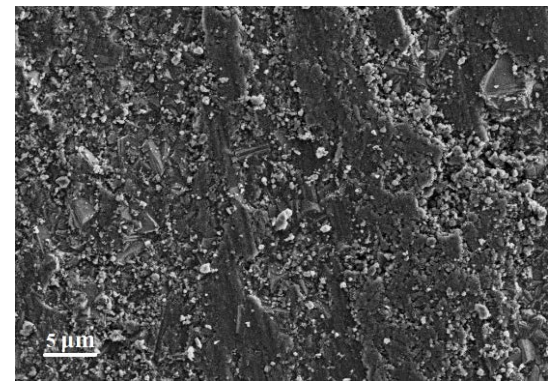

(b)

Figure 6. Wear morphologies of specimens MCD after tribotest. (a) Low magnification; (b) High magnification.

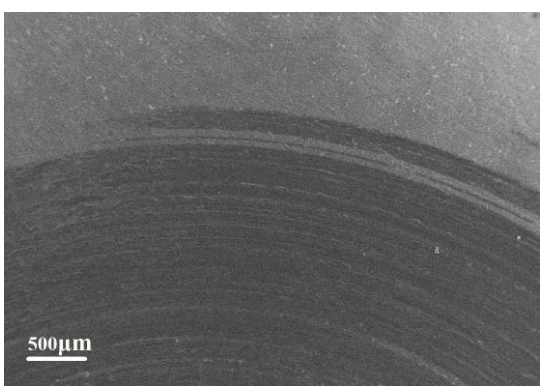

(a)

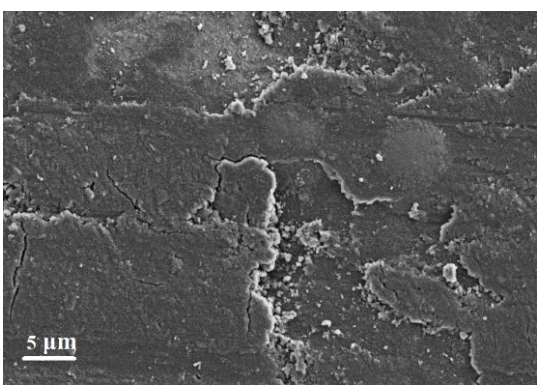

(b)

Figure 7. Wear morphologies of specimens NCD after tribotest. (a) Low magnification; (b) High magnification.

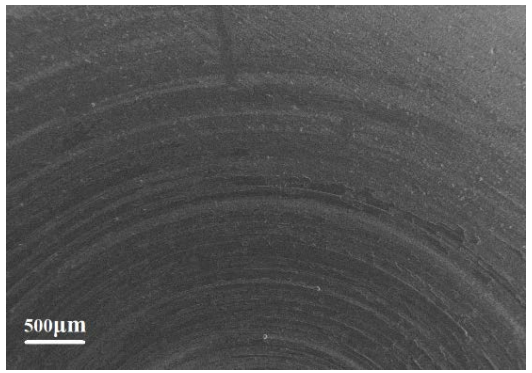

(a)

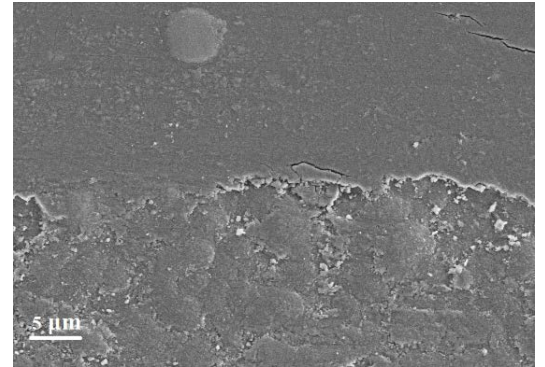

(b)

Figure 8. Wear morphologies of specimens MCD/NCD after tribotest. (a) Low magnification; (b) High magnification.

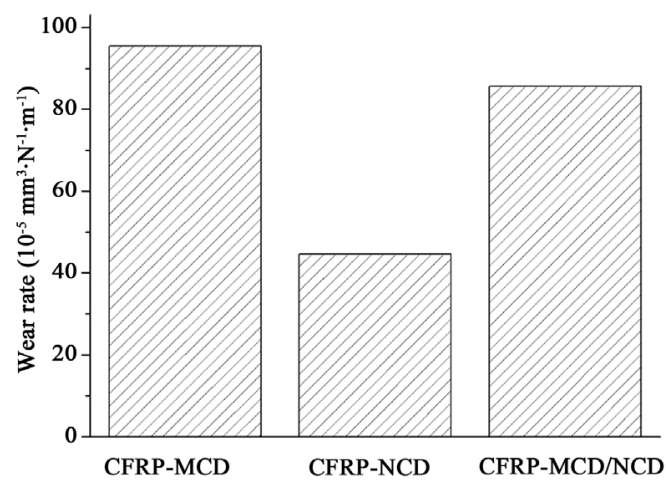

Figure 9. The specific wear rates of CFRP in the tribosystems. 


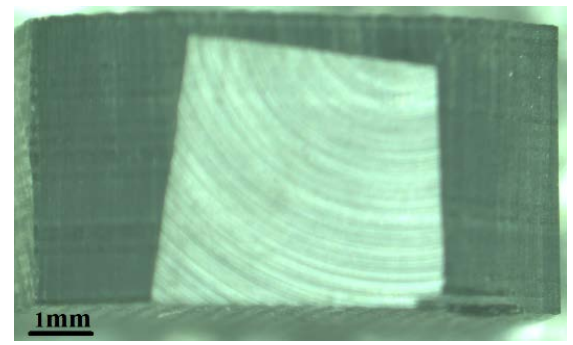

(a)

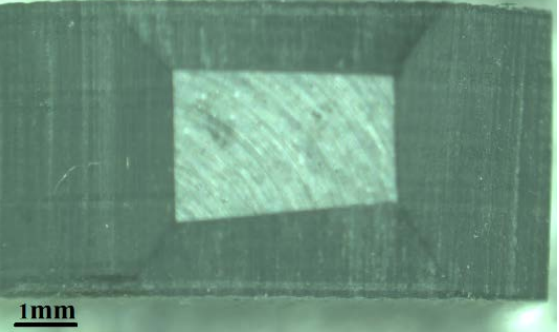

(b)

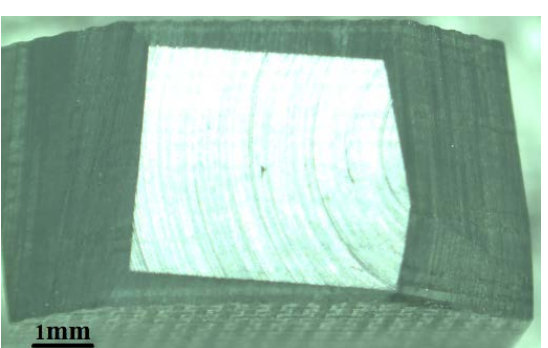

(c)

Figure 10. Wear morphologies of specimens CFRP in different tribo pairs after tribotest. (a) CFRP-MCD; (b) CFRP-NCD; (c) CFRP-MCD/NCD.

$\mathrm{MCD} / \mathrm{NCD}$ displays the large area of contact surface due to the higher hardness of the existence of MCD in the composite coatings.

\section{Conclusion}

The MCD, NCD and MCD/NCD films are deposited on the WC-Co plat substrates, which are applied for tribotests in order to clarify their tribological prosperities with CFRP. The friction coefficient curves of as-fabricated diamond films as functions of the sliding time present two typical stages: an initial sharp peak and a rapid descending to a dynamic equilibrium steady-state stage. The worn surfaces and wear rates of contacted surfaces in the MCD-CFRP, NCD-CFRP and MCD/NCD-CFRP are evaluated to characterize the tribological properties. Compared with the MCD, the NCD shows $22.6 \%$ lower COF, while the $\mathrm{COF}$ of $\mathrm{MCD} / \mathrm{NCD}$ drops as much as $58.1 \%$, due to the smoother surface of NCD and MCD/NCD. As to the MCD/NCD, the MCD films located between WC-Co substrate and NCD could lead to the higher hardness than the monolayer MCD, which improve the wear resistant of MCD/NCD. The main wear mechanism is found to be abrasive wear in the MCD-CFRP tribo pairs with the fracture carbon fibers on MCD samples, which suggests that MCD coated tools may cause higher cutting force during CRRP machining.

\section{Acknowledgements}

This research was funded by Fundamental Research Funds for the Central Universities, grant number 2232019D3-35, the Natural Science Foundation of Shanghai, grant number 18ZR1401100 and Shanghai Key Lab of Advanced Manufacturing Environment, grant number KT20150901. 


\section{Conflicts of Interest}

The author declares no conflicts of interest regarding the publication of this paper.

\section{References}

[1] Zhu, R.H., Miao, J.Y., Liu, J.L., Chen, L.X., Guo, J.C., Hua, C.Y., Ding, T., Lian, H.K. and Li, C.M. (2014) High Temperature Thermal Conductivity of Free-Standing Diamond Films Prepared by DC Arc Plasma Jet CVD. Diamond and Related Materials, 50, 55-59. https://doi.org/10.1016/j.diamond.2014.09.007

[2] Gao, J., Hei, H., Shen, Y., Liu, X., Tang, B., He, Z., et al. (2015) Temperature Dependence of W Metallic Coatings Synthesized by Double Glow Plasma Surface Alloying Technology on CVD Diamond Films. Applied Surface Science, 356, 429-437. https://doi.org/10.1016/j.apsusc.2015.08.093

[3] Shen, B., Sun, F.H., Xue, H.G., Chen, M. and Zhang, Z.M. (2009) Study on Fabrication and Cutting Performance of High Quality Diamond Coated PCB Milling Tools with Complicated Geometries. Surface Engineering, 25, 70-76.

[4] Ma, Y.P., Sun, F.H., Xue, H.G., Zhang, Z.M. and Chen, M. (2007) Deposition and Characterization of Nanocrystalline Diamond Films on Co-Cemented Tungsten Carbide Inserts. Diamond and Related Materials, 16, 481-485. https://doi.org/10.1016/j.diamond.2006.09.020

[5] Lu, P., Gomez, H., Xiao, X., Lukitsch, M., Durham, D., Sachdeve, A. and Chou, K. (2013) Coating Thickness and Interlayer Effects on CVD-Diamond Film Adhesion to Cobalt-Cemented Tungsten Carbides. Surface and Coatings Technology, 215, 272-279. https://doi.org/10.1016/j.surfcoat.2012.08.093

[6] Benarioua, Y., Lesage, J., Chicot, D. and Moisan, M. (2013) Structure and Hardness of Diamond Films Deposited on WC-Co by CVD Technique. Surface and Coatings Technology, 227, 70-74. https://doi.org/10.1016/j.surfcoat.2013.04.005

[7] Booth, L., Catledge, S.A., Nolen, D., Thompson, R.G. and Vohra, Y.K. (2011) Synthesis and Characterization of Multilayered Diamond Coatings for Biomedical Implants. Materials, 4, 857-868. https://doi.org/10.3390/ma4050857

[8] Xu, J. and El Mansori, M. (2016) Experimental Study on Drilling Mechanisms and Strategies of Hybrid CFRP/Ti Stacks. Composite Structures, 157,461-482. https://doi.org/10.1016/j.compstruct.2016.07.025

[9] Geng, D., Zhang, D., Li, Z. and Liu, D. (2017) Feasibility Study of Ultrasonic Elliptical Vibration-Assisted Reaming of Carbon Fiber Reinforced Plastics/Titanium Alloy Stacks. Ultrasonics, 75, 80-90. https://doi.org/10.1016/j.ultras.2016.11.011

[10] Kuo, C., Wang, C. and Ko, S. (2017) Wear Behaviour of CVD Diamond-Coated Tools in the Drilling of Woven CFRP Composites. Wear, 398-399, 1-12. https://doi.org/10.1016/j.wear.2017.11.015

[11] Henerichs, M., Voß, R., Harsch, D., Kuster, F. and Wegener, K. (2014) Tool Life Time Extension with Nano-Crystalline Diamond Coatings for Drilling Carbon-Fibre Reinforced Plastics (CFRP). Procedia CIRP, 24, 125-129. https://doi.org/10.1016/j.procir.2014.07.144

[12] Klinkova, O., Rech, J., Drapier, S. and Bergheau, J.M. (2011) Characterization of Friction Properties at the Workmaterial/Cutting Tool Interface during the Machining of Randomly Structured Carbon Fibers Reinforced Polymer with Carbide Tools under Dry Conditions. Tribology International, 44, 2050-2058.

https://doi.org/10.1016/j.triboint.2011.09.006 
[13] Mondelin, A., Furet, B. and Joël, R. (2010) Characterisation of Friction Properties between a Laminated Carbon Fibres Reinforced Polymer and a Monocrystalline Diamond under Dry or Lubricated Conditions. Tribology International, 43, 1665-1673. https://doi.org/10.1016/j.triboint.2010.03.015

[14] Lei, X.L., He, Y. and Sun, F.H. (2018) Effect of Diamond Interlayer on the Tribological Properties of TiAlN Film Sliding against Carbon Steel. Surface Review and Letters, 25, Article ID: 1950001. https://doi.org/10.1142/S0218625X1950001X

[15] Wang, X., Shen, X., Sun, F. and Shen, B. (2016) Tribological Properties of MCD Films Synthesized Using Different Carbon Sources When Sliding against Stainless Steel. Tribology Letters, 61, 21. https://doi.org/10.1007/s11249-015-0639-6

[16] Wang, X., Wang, C., Shen, X. and Sun, F. (2019) Tribological Behaviors of the Diamond Films Sliding against the T800/X850 CFRP Laminates. Wear, 418-419, 191-200. https://doi.org/10.1016/j.wear.2018.12.007

[17] Yang, T.S., Lai, J.Y., Cheng, C.L. and Wong, M.S. (2001) Growth of Faceted, Ballas-Like and Nanocrystalline Diamond Films Deposited in $\mathrm{CH}_{4} / \mathrm{H}_{2} / \mathrm{ArMPCVD}$. Diamond and Related Materials, 10, 2161-2166. https://doi.org/10.1016/S0925-9635(01)00495-2

[18] Mohr, M., Daccache, L., Horvat, S., Kai, B., Jacob, T. and Fecht, H.J. (2017) Influence of Grain Boundaries on Elasticity and Thermal Conductivity of Nanocrystalline Diamond Films. Acta Materialia, 122, 92-98. https://doi.org/10.1016/j.actamat.2016.09.042

[19] Wang, L., Lei, X., Shen, B., Sun, F. and Zhang, Z. (2013) Tribological Properties and Cutting Performance of Boron and Silicon Doped Diamond Films on Co-Cemented Tungsten Carbide Inserts. Diamond and Related Materials, 33, 54-62. https://doi.org/10.1016/j.diamond.2013.01.004 